\title{
Economic crises and suicides between 1970 and 2011: time trend study in 21 developed countries
}

\author{
Sanna Huikari, ${ }^{1}$ Jouko Miettunen, ${ }^{2,3}$ Marko Korhonen ${ }^{1}$
}

- Additional material is published online only. To view please visit the journal online (http://dx.doi.org/10.1136/ jech-2018-210781)

'Department of Economics, University of Oulu, Oulu, Finland ${ }^{2}$ Center for Life Course Health Research, University of Oulu, Finland

${ }^{3}$ Medical Research Centre Oulu, Oulu University Hospital and University of Oulu, Finland

\section{Correspondence to}

Dr Sanna Huikari, Department of Economics, PO Box 4600, 90014 University of Oulu, Finland; sanna.huikari@oulu.fi

Received 16 March 2018 Revised 28 October 2018 Accepted 13 December 2018 Published Online First 28 January 2019

\begin{abstract}
Background Existing research on the relationship between economic recessions and suicides has almost completely concentrated on the most recent global financial crisis (2008). We provide the most comprehensive explanation to date of how different types of economic/financial crises since 1970 have affected suicides in developed countries.
\end{abstract}

Methods Negative binomial regressions were used to estimate what the suicide rates would have been during and 1 year after each crisis began in 21 Organisation for Economic Co-operation and Development countries from 1970 to 2011 if the suicide rates had followed the pre-crisis trends.

Results We found that every economic/financial crisis since 1970, except the European Exchange Rate Mechanism crisis in 1992, led to excess suicides in developed countries. Among males, the excess suicide rate (per 100000 persons) varied from $1.1(95 \% \mathrm{Cl} 0.7$ to 1.5 ) to 9.5 (7.6 to 11.2) and, among females, from 0 to 2.4 (1.9 to 2.9). For both sexes, suicides increased mostly due to stock market crashes and banking crises. In terms of actual numbers, the post-1969 economic/ financial crises caused $>60000$ excess suicides in the 21 developed countries. The Asian financial crisis in 1997 was the most damaging crisis when assessed based on excess suicides.

Conclusions Evidence indicates that, when considered in terms of effects on suicide mortality, the most recent global financial crisis is not particularly severe compared with previous global economic/financial crises. The distinct types of crises (ie, banking, currency and inflation crises, and stock market crashes) have different effects on suicide.

\section{INTRODUCTION}

The global financial crisis of 2008 ('the Great Recession') was by many measures the worst crisis since the Great Depression of the 1930s. Evidence shows that the formerly declining suicide trend became markedly reversed in many Western countries after 2008. Barr et $a l^{1}$ estimated that, in England, the economic recession in 2008-2010 caused approximately 1000 excess suicides. Chang et al ${ }^{2}$ estimated that there were almost 5000 excess suicides across 54 countries in 2009 (calculated based on the trend for 2000-2007). Furthermore, suicide rates in European countries (especially in Greece) increased significantly after the global economic recession in $2008 .^{3-10}$

In a series of papers by Ruhm, ${ }^{11-13}$ Neumayer, ${ }^{14}$ Tapia Granados, ${ }^{15}$ and Tapia Granados and Ionides ${ }^{16}$ show that economic recessions are associated with lower mortality. Also, Cutler et al ${ }^{17}$ present that large recessions increase mortality. In recent studies, ${ }^{18} 19$ there is evidence that total mortality has shifted from strong procyclical to unrelated to macroeconomic factors. The results related to suicide were mixed. Ruhm ${ }^{11}$ presented that the occurrence of suicide increased when economic conditions decline. Neumayer ${ }^{14}$ found that also suicides were lower in recessions. We should also emphasise that economic crises lead to a reduction of social networks, increase mental health problems, weaken self-esteem and reduce the possibilities to use one's skills. A well-established finding in the literature is that mental disorders play a significant role in almost all suicides. ${ }^{20}$

Unlike total mortality or other causes of death that are primarily proxies for physical health or non-disease sources of death, suicide mortality is generally reported to be countercyclical or neutral. ${ }^{21121-23}$ These results raise the possibility that worsening economic conditions have negative effects on some facets of mental health. ${ }^{11}$ Gunnell and Chang ${ }^{23}$ list stressors that are closely linked to economic recessions, such as increases in unemployment, difficulties in keeping up with mortgage repayments, and increased stress and workload of those who remain in work after staffing reductions. Increased stress could result in impaired mental health, lead to self-harm or increase alcohol abuse, all of which are major risk factors for suicide.

Previous studies on the relationship between economic recessions and suicides have almost completely concentrated on the most recent global financial crisis. There are a few notable exceptions. Luo et $a l^{24}$ explored the association between suicide and business cycles with the US age-specific data from 1928 to 2007 . They find that suicide rate generally rose during recessions, although different age groups responded differently. Blasco-Fontecilla et $a l^{25}$ find that gross domestic product (GDP) adjusted for purchasing power parity per capita strongly correlates to suicide rates in their study with $10 \mathrm{WHO}$ regions during the past 30 years.

We took a broader view by comparing the severities of different types of large economic/ financial crises in developed countries since 1970. By exploring the effects of these crises in terms of excess suicides, we were able to compare how suicide rates responded to the major global level economic crises. In addition, we examined whether different types of economic or financial crises (stock market, currency, inflation or banking crises) have affected differently on the suicides. 


\section{METHODS}

\section{Data}

We used data on economic/financial crises and suicides from 21 Organisation for Economic Co-operation and Development (OECD) countries for the period 1970-2011. The included countries were Australia, Austria, Belgium, Canada, Denmark, Finland, France, Germany, Greece, Ireland, Italy, Japan, the Netherlands, New Zealand, Norway, Portugal, Spain, Sweden, Switzerland, the UK, and the USA. The suicide data were collected from the WHO Mortality Database. ${ }^{26}$ The database includes the number of sex-specific suicide deaths by country, as coded according to the International Classification of Diseases (7th, 8th, 9th and 10th revisions). Mid-year sex-specific population counts were obtained from the same database. We used these population counts to compute the actual, expected and excess suicide rates.

The data on unemployment and growth rates of the real GDP per capita were collected from the Conference Board Total Economy Database ${ }^{27}$ and the online database of the OECD, OECD.Stat. ${ }^{28}$

\section{Measures of economic/financial crises}

We concentrated on the most severe global economic/financial crises since 1970. The included crises were the oil-shock recession of 1974, inflation-defeating recession of 1982, Black Monday crash of 1987, Nordic banking crisis of 1991, European Exchange Rate Mechanism (ERM) crisis of 1992, Asian financial crisis of 1997, Dot-com bubble (IT bubble) of 2001, global financial crisis of 2008 ('the Great Recession') and Eurozone debt crisis of 2010. An important feature of these crises is that they were unexpected. Detailed histories of these economic/ financial crises can be found, for example, in Kindleberger and Aliber $^{29}$ (see online supplementary data for a concise description of each crisis).

The distinct categories of economic/financial crisis used in our analysis were banking, currency and inflation crises, and stock market crashes. We use the definitions of Reinhart and Rogoff ${ }^{30}$ for each type of crisis (see online supplementary data for the specific definitions).

There are some notable differences between how these distinct types of crises are related to suicides. Shiller ${ }^{31}$ explored people's perception of the costs of inflation and found that the major concern of high inflation is the concern of a reduction of individual's standard of living. The most damaging currency crisis occurs when there is initially a fixed exchange rate and individuals and financial agents have made their economic decisions under the assumption that this fixed exchange rate will maintain in the future. For example, during the South Asian currency crisis in 1997, several exchange rates depreciated $>50 \%$ within a few months after the speculative attack took place. When stock markets crash, a large number of individuals suffer major losses in their wealth and savings. For example, the stock market crash during the Great Depression led to impulsive suicides by bankers because of acute financial losses. Also, the wealth losses after the 2008 stock market crash increased significantly depression as presented in McInerney et al. ${ }^{32}$ Compared with the other types of crisis, the banking crises are distinctive in a way that they affect the whole economic system and, hence, have impacts on all individuals. Furthermore, the banking crises have serious effects on the trust and confidence, which are the most important bases of the entire financial system.

\section{Statistical analyses}

We used negative binomial regressions to assess excess suicides during and 1 year after each economic/financial crisis erupted.
The same approach is used, for example, in Barr et al, ${ }^{1}$ Cha et $a l,{ }^{33}$ Chang et $a l,{ }^{2}$ Laanani et $a l^{34}$ and Reeves et al. ${ }^{35}$

First, we estimated the 10-year linear suicide trends before each economic/financial crisis in each of the 21 OECD countries using dummy variables for crisis years and for the 1 year after the crises erupted. From these models, we obtained the estimated rate ratios for actual and expected suicides, along with their CIs. The statistical significance of the rate ratios was set at a $p$ value $<0.05$. Based on the rate ratio estimations, we calculated the expected numbers of suicides, that is, what the suicide numbers would have been if the pre-crises trends had continued. The estimates of the numbers of excess suicides were then obtained by quantifying the deviation between the actual and expected numbers of suicides (given the pre-crisis trends) (see online supplementary data for further methodological details). All the analyses were conducted with Stata V.14 (StataCorp).

The relationship between economic/financial crisis and suicide should be considered with care because an economic/financial crisis can impact on suicide, for example, via an increase in unemployment. ${ }^{34}$ It is important to note that economic/financial crises typically involve periods when unemployment increases and output declines. This implies that during an economic crisis all 'excess' suicides are probably not directly the result of the crisis itself. An economic/financial crisis could affect suicide due to concomitant features of the crisis, for example, by increasing unemployment or decreasing income. Also, Laanani et $a l^{34}$ argue that the high correlation between the impact of unemployment and the impact of the other features of the economic crisis (or 'crisis effect') makes it difficult to study them independently. For this reason, we estimated excess suicides after including variables for unemployment and GDP as controls (the results without these covariates are presented in online supplementary table S1-S3). In this way, we were able to assess whether there were excess suicides attributable to a 'crisis effect' beyond the unemployment and income effects. The resulting model, which was estimated for each country and separately for male and female population, was as follows:

$$
\begin{aligned}
\ln \left(\lambda_{t}\right)=\ln \left(E\left(s u i_{t}\right)\right) & =\ln \left(p o p_{t}\right)+\alpha+\beta t+\delta u e_{t} \\
& +\mu \ln \left(y_{t}\right)+\gamma \mathbf{I}_{\{t=\text { crisis year }\}}
\end{aligned}
$$

where $t$ is the year, sui $i_{t}$ is the number of suicides that occurred, $p o p_{t}$ is the population size, $u e_{t}$ is unemployment rate and $\ln \left(y_{t}\right)$ natural logarithm of GDP per capita. The $\alpha, \beta, \delta$ and $\mu$ values are coefficients estimated from the data. The term involving the natural logarithm of the population size, $\ln (p o p)$, is called the offset variable, and it was included in the model to adjust for annual changes in population figures. The dummy variable for economic/financial crisis for a particular year (or the year after the crisis erupted) is denoted as $\mathrm{I}_{\{t=\text { crisis year }\}}$.

The rate ratios between the actual and expected number of suicides, $\frac{\text { sui }_{t}}{\lambda_{\text {crisis year }}}$, were obtained from the exponential of $\gamma$. These rate ratios were then used to calculate the expected number of suicides, $\lambda_{\text {crisis year }}$, that is, what the number of suicides would have been if the preceding 10-year trend had continued. The number of excess suicides was obtained based on the positive deviation between the actual and expected number of suicides. All the estimated rate ratios which were used in calculations associated to global crises are presented in the third column of online supplementary table S4. 
Table 1 Male and female excess suicide rates associated with major economic crises* (during and/or 1 year after) in 21 Organisation for Economic Co-operation and Development countries

\begin{tabular}{|c|c|c|c|c|}
\hline Crisis & Male excess suicide rate $\ddagger, \mathrm{n}(95 \% \mathrm{Cl})$ & $\% \S$ & Female excess suicide rate, $\mathrm{n}(95 \% \mathrm{Cl})$ & $\%$ \\
\hline Oil-shock recession, 1974 & $1.4(0.8$ to 2.0$)$ & 17.8 & $0.8(0.4$ to 1.2$)$ & 16.0 \\
\hline Inflation-defeating recession, 1982 & $4.1(3.2$ to 4.9$)$ & 21.4 & $1.0(0.6$ to 1.4$)$ & 12.5 \\
\hline Without Japan & $1.5(0.5$ to 2.4$)$ & 17.3 & $0.6(0.2$ to 0.9$)$ & 26.2 \\
\hline Black Monday crash, 1987 & $3.4(0.5$ to 5.9$)$ & 15.1 & - & \\
\hline Nordic banking crisis, 1991 & $3.3(0.3$ to 5.8$)$ & 24.1 & - & \\
\hline European Exchange Rate Mechanism crisis, 1992 & - & & - & \\
\hline Asian financial crisis, 1997 & 9.5 (7.6 to 11.2$)$ & 35.0 & $2.4(1.9$ to 2.9$)$ & 23.1 \\
\hline Without Japan & - & & $1.4(0.8$ to 2.0$)$ & 31.3 \\
\hline Dot-com bubble, 2001 & $3.0(1.2$ to 4.7$)$ & 20.5 & $0.4(0.2$ to 0.5$)$ & 8.2 \\
\hline Global financial crisis, 2008 & $2.7(1.0$ to 4.0$)$ & 26.5 & - & \\
\hline Eurozone debt crisis, 2010 & $1.1(0.7$ to 1.5$)$ & 5.9 & $0.9(0.5$ to 1.3$)$ & 17.9 \\
\hline
\end{tabular}

${ }^{*}$ Additional covariates in estimated regression models were unemployment and natural logarithm of gross domestic product per capita.

‡Excess rates are calculated as the difference between the actual suicide rate and the rate that would have been expected on the basis of the preceding 10 -year trend. $\S \%$ denotes increase in suicide rate compared with the suicide rate that would have been expected based on the preceding trend.

\section{RESULTS}

Online supplementary figure S1 displays the population-weighted suicide rates (in all of our sample countries combined) for both genders and the world aggregate crisis index ${ }^{30}$ from 1960 to 2012. The effects of economic/financial crises in terms of excess suicides are presented in table 1 . By measuring the severity of crises in terms of excess suicide rates, it is clear that the Asian financial crisis (1997) was the most severe crisis (the lower limits of $95 \%$ CIs exceed the upper limits of $95 \%$ CIs of excess suicide numbers in any other crisis). The excess suicide rate (per 100 000 persons) was 9.5 (95\% CI 7.6 to 11.2 ) for males and 2.4 (1.9 to 2.9) for females. This implies a $35 \%$ increase in male suicide rates and a $23.1 \%$ increase in female suicide rates during and/or 1 year after the crisis compared with the suicide rate that would have been expected based on the preceding trend. Almost all of these excess suicides occurred in Japan. When we excluded Japan, the excess suicide rate was not statistically significant (at the $5 \%$ significance level) for males and it was 1.4 (0.8 to 2.0) for females. Thus, male excess suicides increased by $0.0 \%$ but for females they increased by $31.3 \%$ with respect to the expected rate. The Asian financial crisis seems to have had a huge effect in terms of increasing women's suicides in developed countries irrespective of whether Japan was included.

High excess suicide rates also occurred after the inflation-defeating recession (1982). The excess suicide rate for males was around 4.1 (95\% CI 3.2 to 4.9$)$ and for females around 1.0 (0.6 to 1.4 ), implying a $21.4 \%$ increase in male suicides and a $12.5 \%$ increase in female suicides (compared with the expected rates). However, like for the Asian financial crisis, the excess suicide rates dropped markedly when we disregarded Japan, being 1.5 (0.5 to 2.4 ) for males and $0.6(0.2$ to 0.9$)$ for females. Nevertheless, the percentage increase in suicide rates (compared with the expected rates) stayed high for males, at $17.3 \%$, and it even increased to $26.2 \%$ for females. This indicates that the effect of the crisis among females in Japan was relatively small compared with the other countries affected by the crisis.

The stock market crash in October 1987 (which started on so-called Black Monday) and the Nordic banking crisis in 1991 were two other major crises that led to high male excess suicide rates. In these crises, however, there were not huge numbers of excess suicides in Japan. The excess rate for males was 3.4 (95\% CI 0.5 to 5.9$)$ after the stock market crash and 3.3 (0.3 to 5.8) after the Nordic banking crisis. Interestingly, for females, the excess suicide rates were not statistically significant after either crisis. For males, the stock market crash caused a $15.1 \%$ increase and the Nordic banking crisis caused a $24.1 \%$ increase in the suicide rate (compared with the expected rate). The ERM crisis in 1992 was the only crisis that was not statistically significantly (at the 5\% significance level) associated with excess suicides for either males or females.

It is noteworthy that the economic crises in the 2000s led to somewhat lower excess suicide rates compared with the earlier major economic crises since 1970. For example, the global financial crisis of 2008 led to an excess suicide rate of 2.7 (95\% CI 1.0 to 4.0 ) for males and a non-significant rate for females. This implies a percentage increase in the suicide rate (compared with the expected rate) of $26.5 \%$ for males, which is the second highest percentage increase among the crises analysed. The bursting of the Dot-com bubble in the early 2000s resulted in a male excess suicide rate of 3.0 (1.2 to 4.7$)$ and a female excess suicide rate of $0.4(0.2$ to 0.5$)$. Expressed in the terms of an increase in suicides compared with what would have been anticipated based on preceding trends, the increase was $20.5 \%$ for males and $8.2 \%$ for females. Furthermore, the results for the Eurozone debt crisis were among the least severe, with an excess suicide rate of 1.1 (0.7 to 1.5$)$ for males and 0.9 (0.5 to 1.3$)$ for females, corresponding to percentage increases of $5.9 \%$ and $17.9 \%$ in the expected suicide rates for males and females, respectively.

For robustness, we conducted separate regressions using different covariates, using 15-year trend, and only for those of working age (25-64 years). The estimates of suicide rate ratios are presented in online supplementary table S4-S9. In addition, we have replicated table 1 on the basis of the preceding 8 -year and 15-year trend, and the results are presented in online supplementary table S10. We find that our 10-year time trend estimates for the whole population are relatively robust since the rate ratio estimates do not substantially change across regressions. Further, we conduct placebo tests to validate our model approach. The estimations were done for the periods 1955-1965 and 19621973. The placebo regression results are presented in online supplementary table S11-S12. The estimated numbers of excess suicides suggest that predicted suicide numbers do not substantially deviate from actual suicide numbers that occurred (ie, there are no excess suicides) in 'fake' crash years of 1965 and 1973. 
Table 2 Number of male and female excess suicides associated with major economic crises* (during and/or 1 year after) in 21 Organisation for Economic Co-operation and Development countries

\begin{tabular}{|c|c|c|}
\hline Crisis & $\begin{array}{l}\text { Male excess suicidest, } \\
\mathrm{n}(95 \% \mathrm{Cl})\end{array}$ & $\begin{array}{l}\text { Female excess } \\
\text { suicides, } \mathrm{n}(95 \% \mathrm{Cl})\end{array}$ \\
\hline Oil-shock recession, 1974 & 807 (470 to 1118 ) & 503 (256 to 732 ) \\
\hline $\begin{array}{l}\text { Inflation-defeating recession, } \\
1982\end{array}$ & 3438 (2703 to 4128$)$ & 1024 (610 to 1409$)$ \\
\hline Without Japan & 388 (125 to 622$)$ & 229 (91 to 348$)$ \\
\hline Black Monday crash, 1987 & $470(67$ to 811$)$ & - \\
\hline Nordic banking crisis, 1991 & 59 (6 to 103$)$ & - \\
\hline $\begin{array}{l}\text { European Exchange Rate } \\
\text { Mechanism crisis, } 1992\end{array}$ & - & - \\
\hline Asian financial crisis, 1997 & 5800 (4647 to 6877$)$ & 3301 (2554 to 4008) \\
\hline Without Japan & - & 133 (77 to 182 ) \\
\hline Dot-com bubble, 2001 & 4585 (1782 to 7076$)$ & 795 (431 to 1116) \\
\hline Global financial crisis, 2008 & 1121 (404 to 1688 ) & - \\
\hline Eurozone debt crisis, 2010 & 2584 (1674 to 3475$)$ & 874 (477 to 1193 ) \\
\hline
\end{tabular}

${ }^{*}$ Additional covariates in estimated regression models were unemployment and natural logarithm of gross domestic product per capita.

†Numbers of excess suicides were calculated as the difference between the actual number of suicides and the number that would have been expected on the basis of the preceding 10-year trend.

The gender-specific numbers of excess suicides associated with major economic crises are presented in table 2. The Asian financial crisis (1997) seems to have caused the most excess suicides for both males and females. Our results show that there were $>9000$ total excess suicides (compared with the expected number if the pre-crisis trends had continued). Japan accounted for almost all these suicides. However, when we disregarded Japan, the crises in the 2000s, namely the Dot-com bubble (2001), the global financial crisis (2008) and Eurozone debt crisis (2010), caused the largest numbers of excess suicides. The total numbers of excess suicides in these crises were 5380 (95\% CI 2213 to 8192), 1121 (404 to 1688) and 3458 (2151 to 4668), respectively. The inflation-defeating recession (1982) also led to a high number of excess suicides, causing almost 4500 excess suicides when Japan was included in the analysis. The number without Japan was only about 600 . One possible explanation for excess suicides in Japan was a drop in the NIKKEI index after several years of increase in the early 1980s.
The results regarding the severity of the crises (in terms of absolute numbers rather than excess suicide rates) differ somewhat to what is presented in table 1 . While table 1 shows that excess suicide rates were not particularly high for the crises in the 2000 s, the numbers of excess suicides indicate that these most recent crises led to relatively high numbers of excess suicides. The reason is that these crises led to excess suicides in countries where the population is large, such as the USA. Thus, when comparing the severity of each crisis, it is crucial to also consider this scale effect.

There is a notable gender difference in the relationship between economic/financial crises and suicides. On average, men account for the majority of excess suicides after major global economic/financial crises. The number of male excess suicides ranged from 59 to 5800 (95\% CI 6 to 7076), whereas the equivalent numbers for females were from 133 to 3301 (77 to 4008). However, when comparing excess suicides in relative terms (ie, relative to their trend-based values, in terms of percentage increases), we did not find any systematic gender difference in excess suicides.

Table 3 shows the effects of distinct types of crises in terms of excess suicide rates and numbers across the 21 countries. Banking crises and stock market crashes seem to be the most fatal types when the severity of each crisis is measured as the number of excess suicides. Although the estimated suicide rates in each crisis fall in 95\% CIs of all other crises, the lower limits of excess numbers for banking and stock market crises exceed the upper limits of excess numbers of currency and inflation crisis. Only when comparing the excess numbers due to stock market and inflation crises among females there is overlapping in the excess suicide numbers. After the banking crises, the average excess suicide rate was 1.6 (95\% CI 0.6 to 2.5$)$ for males and 0.9 (0.4 to 1.3 ) for females. Since 1970 , banking crises have solely accounted for $>13000$ excess suicides. The majority of these, 8889 (3564 to 13 854), were among males.

The effects of stock market crashes in terms of excess suicide rates were estimated to be 2.2 (95\% CI 0.8 to 3.4) for males and 1.1 (0.5 to 1.6) for females. The number of excess suicides due to stock market crashes was 12459 (4625 to 19 560) for males and 2968 (1260 to 4497) for females. Hence, during stock market crashes, there were also more excess suicides for males.

After currency crises, the excess suicide rates were $1.2(95 \%$ CI 0.3 to 2.0 ) for males and $0.6(0.3$ to 0.8$)$ for females. The numbers of excess suicides were 1726 (504 to 2867) and 974

Table 3 Male and female excess suicide rates and numbers associated with different economic crises* (during and/or 1 year after) in 21 Organisation for Economic Co-operation and Development countries

\begin{tabular}{|c|c|c|c|c|c|c|}
\hline Crisis & $\begin{array}{l}\text { Male excess suicide } \\
\text { ratet¥, } \mathrm{n}(95 \% \mathrm{Cl})\end{array}$ & $\% \S$ & $\begin{array}{l}\text { Female excess suicide } \\
\text { rate, } \mathrm{n}(95 \% \mathrm{CI})\end{array}$ & $\%$ & $\begin{array}{l}\text { Male excess suicidesף, } n \\
(95 \% \mathrm{Cl})\end{array}$ & $\begin{array}{l}\text { Female excess suicides, } n \\
(95 \% \mathrm{Cl})\end{array}$ \\
\hline Currency & $1.2(0.3$ to 2.0$)$ & 8.5 & $0.6(0.3$ to 0.8$)$ & 13.5 & 1726 (504 to 2867) & 974 (522 to 1386) \\
\hline Inflation & - & - & $1.4(0.2$ to 2.1$)$ & 67.4 & - & 22 (4 to 33 ) \\
\hline Stock market crash & 2.2 (0.8 to 3.4) & 13.7 & $1.1(0.5$ to 1.6$)$ & 17.8 & 12459 (4625 to 19560$)$ & 2968 (1260 to 4497) \\
\hline Banking crisis & $1.6(0.6$ to 2.5$)$ & 8.7 & $0.9(0.4$ to 1.3$)$ & 13.4 & 8889 (3564 to 13854$)$ & 4135 (1981 to 6077) \\
\hline Stock and/or Banking & $2.8(1.6$ to 4.0$)$ & 15.5 & $1.3(0.7$ to 1.9$)$ & 17.4 & 40711 (22280 to 57604$)$ & 15048 (7883 to 21511$)$ \\
\hline Without Japan & $1.9(0.8$ to 2.8$)$ & 11.3 & $0.9(0.4$ to 1.3$)$ & 15.7 & 20808 (8565 to 31990$)$ & 5991 (2550 to 9036) \\
\hline Stock and/or banking and/or currency & $2.6(1.4$ to 3.8$)$ & 15.1 & $1.2(0.6$ to 1.7$)$ & 17.1 & 43932 (23404 to 62737$)$ & 16492 (8580 to 23628 ) \\
\hline Without Japan & $1.8(0.7$ to 2.7$)$ & 11.3 & $0.8(0.4$ to 1.2$)$ & 15.6 & 24029 (9689 to 37123$)$ & 7434 (3247 to 11153$)$ \\
\hline
\end{tabular}

*Additional covariates in estimated regression models were unemployment and natural logarithm of gross domestic product per capita.

tPer 100000 persons.

$\ddagger$ Excess rates are calculated as the difference between the actual suicide rate and the rate that would have been expected on the basis of the preceding 10 -year trend.

$\S \%$ denotes increase in suicide rate compared with the suicide rate that would have been expected based on the preceding trend.

१Numbers of excess suicides were calculated as the difference between the actual number of suicides and the number that would have been expected on the basis of the preceding 10 -year trend. 
(522 to 1386), respectively. Inflation crises led to an excess suicide rate of 1.4 (0.2 to 2.1$)$ for females and a non-significant rate for males. The numbers of excess suicides related to inflation crises were much milder than for other types of crises, being only 22 (4 to 33 ) for females.

There is a close temporal link between different types of economic crises. To examine the effects on countries facing either a stock market crash, a banking crisis or both at the same time, we combined the results for either stock market crashes or banking crises or instances of both (table 3, fifth row from the top). According to the results, there were almost 56000 more suicides than would have been expected based on the trends that preceded these crises. Approximately $73 \%$ of these excess suicides occurred among males. When we also added the results of currency crises (table 3, second row from the bottom), the estimated number of excess suicides increases to $>60000$. The country-specific results are presented in online supplementary table S13-S14.

\section{DISCUSSION}

We showed that there was a significant increase in suicides during and/or 1 year after every major economic/financial crisis in 21 developed countries since 1970. Uniquely, we revealed that 'the Great Recession' was not particularly disastrous relative to previous crises in terms of global excess suicide figures. We showed that the Asian financial crisis (1997) was the most severe economic/financial crisis compared with any earlier crises since 1970 when severity is measured according to excess suicide rates. It caused nearly 35\% more male suicides and $>23 \%$ more female suicides compared with expected values based on the preceding trends. Also, we found that the effects (in terms of excess suicides) of distinct types of crises have different magnitudes. Banking crises and stock market crashes cause more excess suicides than currency and inflation crises.

The strengths of this study include that we went beyond the effect of the most recent crises, namely the global financial crisis (2008) and Eurozone debt crisis (2010), and compared the effects of all the major economic/financial crises since 1970. Importantly, our results are comparable to those of Chang et $a l^{2}$ and Barr et $a l^{1}$ as we used the same model specification. We also included other economic covariates and used a longer time period in our analysis to alleviate issue with confounding and time biases reported in previous research. ${ }^{36}$ Especially, we showed that the effects of economic crises (in terms of excess suicides) remained at a high level even if we took the population-level unemployment and income variables into account.

The strength of our analysis is the use of the negative binomial regression, which can handle overdispersed data common in rare discrete events, such as suicide frequencies relative to the population. ${ }^{37}$ While the variant of negative binomial model that is used in this study has been found to be very useful in applied work, ${ }^{38}$ there remain a few methodological issues to consider. The use of small sample sizes may cause bias in the dispersion parameter estimates of negative binomial models, which has been shown, for example, by Lord. ${ }^{39}$ Another methodological issue is that the results may be sensitive to the assumed form of the time trend. However, as Laanani $e a^{34}$ point out, the use of a linear time trend is probably the safer choice compared with a non-linear trend when sample periods are relatively short and have few data points. The possibility of non-linear data generating process remains an important further research topic.

There are several limitations in our study. One important limitation is how to distinguish the possible effect of job losses from the crisis effect. Economic/financial crises often led to increased unemployment and decreased material well-being. The negative well-being effects of unemployment are well documented in many previous studies. ${ }^{40-42}$ While we added unemployment as a control variable, we could not fully distinguish the crisis effect from the job-loss effect.

Another limitation is the number of covariates that we took into account. There are probably many factors beyond unemployment and GDP that would affect an individual's decision to commit suicide. For example, an individual's religion, number of children, education and pre-crisis wealth could help them to cope with economic downturns. For example, unemployed individuals who do well financially are not necessarily affected by an economic/financial crisis. On the other hand, divorces, alcohol consumption and debt can influence the likelihood of suicidal behaviour. However, controlling for these covariates would not be methodologically possible due to the limitations associated with estimated parameters in relatively short (eg, 10-year) estimation windows.

The nature of the ecological data limits the interpretation of our results at the individual level. The use of aggregate data makes it impossible to explore whether people who are affected significantly due to economic hardship have some confounding factors, including mental health problems, that might lead them to commit suicide. In using an ecological design, we are also not able to prove direct causality between economic crises and excess suicides. We argue, however, that an ecological design is the most appropriate way to proceed when analysing excess suicides due to global economic crises. Importantly, our study was not designed to assess whether certain groups of people (eg, the unemployed) are more likely to die by suicide than other people (the employed), but rather to assess the impact of different economic/financial crises on national suicide numbers, which justifies the use of an ecological design. Also, due to the long timespan (1970-2011) and the large set of analysed countries (21 OECD members), there are no appropriate individual-level longitudinal data easily available.

While our results indicate that economic crises have an increasing effect on suicides, an important question is whether the effects of economic crises and unemployment on suicides are separable. Since most times the increase in unemployment occurs simultaneously with economic crisis, it is natural to presume that there might be a close interaction between them. Epidemiologists present two basic theories that might explain the increase in association between unemployment and suicide during economic crisis. The causal theory predicts that job loss increases depressions especially during bad economic times precipitating suicide. The selection theory predicts that individuals who are more probable to commit suicide are also more probable to lose their job during crises. ${ }^{434}$ An important future research area is to identify the pure economic crisis effect from the joint effect with unemployment. For policymakers, it is important to differentiate the reasons in order to target right factors with prevention policies.

In conclusion, this study shows that $>60000$ suicides are attributable to the economic/financial crises since 1970. Two main findings emerged from the data. First, our findings indicate that the impact of the most recent global financial crisis (2008) on suicides was not particularly stronger than that of previous major economic/financial crises. Second, stock market crashes and banking crises are the most severe economic crises in terms of excess suicides calculated based on population-level data. 


\section{What is already known on this subject}

- Most published studies on the relation between economic downturns and increase in number of suicides have almost completely concentrated on the most recent global financial crises.

- It is unknown whether similar rises have occurred in countries affected by previous crises and which sex groups are most affected by different financial/economic crises.

\section{What is study adds}

- This study shows that economic/financial crises have led to a significant increase in suicides across developed countries.

- The major economic/financial crises since 1970 caused $>60$ 000 excess suicides across 21 developed countries.

- The impact of the most recent global financial crisis on suicides seems not to have been particularly severe compared with the impacts of previous major economicl financial crises.

- Stock market crashes and banking crises are the most severe economic crises when assessed based on excess suicides associated with economic/financial crises according to population-level data.

Acknowledgements The authors thank Professors Mikko Puhakka and Pertti Haaparanta for their valuable comments. They also thank the participants of Helsinki Centre of Economics Research Macroeconomics and Development Seminar in Helsinki and participants of Health Economics seminar in University of Oulu for useful comments and suggestions.

Contributors $\mathrm{SH}$ and MK contributed to the writing of the manuscript. SH contributed to the statistical design of the study and the interpretation of data. JM contributed to the interpretation of data and revised the manuscript. MK designed and supervised the study.

Funding This work was supported by the Finnish Cultural Foundation [\#00150254 to SH] and Academy of Finland (\#268336 to JM).

Disclaimer The funders had no role in study design, data collection and analysis, decision to publish or preparation of the manuscript.

Competing interests None declared.

Patient consent Not required

Provenance and peer review Not commissioned; externally peer reviewed.

\section{REFERENCES}

1 Barr B, Taylor-Robinson D, Scott-Samuel A, et al. Suicides associated with the 2008-10 economic recession in England: time trend analysis. BMJ 2012;345:e5142.

2 Chang SS, Stuckler D, Yip P, et al. Impact of 2008 global economic crisis on suicide: time trend study in 54 countries. BMJ 2013:347:f5239.

3 Kondilis E, Giannakopoulos S, Gavana M, et al. Economic crisis, restrictive policies, and the population's health and health care: the Greek case. Am J Public Health 2013;103:973-9.

4 McDaid D, Quaglio G, Correia de Campos A, et al. Health protection in times of economic crisis: challenges and opportunities for Europe. J Public Health Policy 2013:34:489-501.

5 Kentikelenis A, Karanikolos M, Papanicolas I, et al. Health effects of financial crisis: omens of a Greek tragedy. Lancet 2011:378:1457-8

6 Kentikelenis A, Papanicolas I. Economic crisis, austerity and the Greek public health system. Eur J Public Health 2012;22:4-5.

7 Kentikelenis A, Karanikolos M, Reeves A, et al. Greece's health crisis: from austerity to denialism. Lancet 2014;383:748-53.

8 Fountoulakis KN, Grammatikopoulos IA, Koupidis SA, et al. Health and the financial crisis in Greece. Lancet 2012;379:1001-2.

9 Fountoulakis KN, Koupidis SA, Siamouli M, et al. Suicide, recession, and unemployment. The Lancet 2013;381:721-2.

10 Antonakakis N, Collins A. The impact of fiscal austerity on suicide: on the empirics of a modern Greek tragedy. Soc Sci Med 2014;112:39-50.
11 Ruhm CJ. Are recessions good for your health? Q J Econ 2000;115:617-50.

12 Ruhm CJ. Good times make you sick. J Health Econ 2003;22:637-58.

13 Ruhm CJ. Healthy living in hard times. J Health Econ 2005;24:341-63.

14 Neumayer E. Recessions lower (some) mortality rates: evidence from Germany. Soc Sci Med 2004;58:1037-47

15 Tapia Granados JA. Recessions and mortality in Spain, 1980-1997. Eur J Popul 2005;21:393-422

16 Tapia Granados JA, Ionides EL. The reversal of the relation between economic growth and health progress: Sweden in the 19th and 20th centuries. J Health Econ 2008:27:544-63.

17 Cutler DM, Huang W, Lleras-Muney A. Economic conditions and mortality: evidence from 200 years of data.

18 Ruhm CJ. Recessions, healthy no more? J Health Econ 2015;42:17-28.

19 Ruhm CJ. Health effects of economic crises. Health Econ 2016:25:6-24.

20 Cavanagh JT, Carson AJ, Sharpe M, et al. Psychological autopsy studies of suicide: a systematic review. Psychol Med 2003;33:395-405.

21 Chang SS, Gunnell D, Sterne JA, et al. Was the economic crisis1997-1998 responsible for rising suicide rates in East/Southeast Asia? A time-trend analysis for Japan, Hong Kong, South Korea, Taiwan, Singapore and Thailand. Soc Sci Med 2009;68:1322-31

22 Stuckler D, Basu S, Suhrcke M, et al. The public health effect of economic crises and alternative policy responses in Europe: an empirical analysis. Lancet 2009:374:315-23.

23 Gunnell D, Chang S-S. Economic recession, unemployment, and suicide. In: O'Connor RC, Pirkis J, eds. The International Handbook of Suicide Prevention. Hoboken: Wiley, 2016:284-300

24 Luo F, Florence CS, Quispe-Agnoli M, et al. Impact of business cycles on US suicide rates, 1928-2007. Am J Public Health 2011;101:1139-46.

25 Blasco-Fontecilla H, Perez-Rodriguez MM, Garcia-Nieto R, et al. Worldwide impact of economic cycles on suicide trends over 3 decades: differences according to level of development. A mixed effect model study. BMJ Open 2012;2:e000785.

26 World Health Organization Statistical Information System. WHO mortality database. http://www.who.int/healthinfo/statistics/mortality_rawdata/en/ (accessed 10 Aug 2016).

27 The conference board total economy database $\mathrm{TM}^{\mathrm{TM}}$ (Original version). http://www. conference-board.org/data/economydatabase/ (accessed 24 Nov 2016).

28 OECD.Stat. The organisation for economic co-operation and development database, OECD. http://stats.oecd.org/ (accessed 24 Nov 2016).

29 Kindleberger CP, Manias ARZ. Panics, and crashes: a history of financial crises. 7th edn. Basingstoke: Palgrave Macmillan, 2015.

30 Reinhart CM, Rogoff KS. This time is different: eight centuries of financial folly. Princeton, NJ: Princeton University Press, 2009.

31 Shiller RJ. Why do people dislike inflation? In: Romer CD, Romer DH. eds. Reducing inflation: motivation and strategy. . Chicago: University of Chicago Press, 1997:Chap. 1. 13-65.

32 Mclnerney M, Mellor JM, Nicholas LH. Recession depression: mental health effects of the 2008 stock market crash.J Health Econ 2013:32:1090-104.

33 Cha ES, Chang SS, Gunnell D, et al. Impact of paraquat regulation on suicide in South Korea. Int J Epidemiol 2016:45:470-9.

34 Laanani M, Ghosn W, Jougla E, et al. Impact of unemployment variations on suicide mortality in Western European countries (2000-2010). J Epidemiol Community Health 2015;69:103-9.

35 Reeves A, Stuckler D, McKee M, et al. Increase in state suicide rates in the USA during economic recession. Lancet 2012;380:1813-4.

36 Parmar D, Stavropoulou C, loannidis JP. Health outcomes during the 2008 financial crisis in Europe: systematic literature review. BMJ 2016;354:i4588.

37 Laszlo AM, Hulman A, Csicsman J, et al. The use of regression methods for the investigation of trends in suicide rates in Hungary between 1963 and 2011. Soc Psychiatry Psychiatr Epidemiol 2015;50:249-56.

38 Cameron C, Trivedi P. Regression Analysis of Count Data. New York, NY: Cambridge University Press, 1998.

39 Lord D. Modeling motor vehicle crashes using Poisson-gamma models: examining the effects of low sample mean values and small sample size on the estimation of the fixed dispersion parameter. Accid Anal Prev 2006:38:751-66.

40 Nordt C, Warnke I, Seifritz E, et al. Modelling suicide and unemployment: a longitudinal analysis covering 63 countries, 2000-11. Lancet Psychiatry 2015;2:239-45.

41 Blakely TA, Collings SC, Atkinson J. Unemployment and suicide. Evidence for a causal association? J Epidemiol Community Health 2003;57:594-600.

42 Milner A, Morrell S, LaMontagne AD. Economically inactive, unemployed and employed suicides in Australia by age and sex over a 10-year period: what was the impact of the 2007 economic recession? Int J Epidemiol 2014;43:1500-7.

43 Mäki N, Martikainen P. A register-based study on excess suicide mortality among unemployed men and women during different levels of unemployment in Finland. $J$ Epidemiol Community Health 2012;66:302-7.

44 Corcoran P, Arensman E. Suicide and employment status during Ireland's Celtic Tige economy. Eur J Public Health 2011:21:209-14. 